\title{
Determining the properties of multi-range semi-tubular self-piercing riveted joints
}

\author{
Fabian Kappe $^{1}$ (1) Simon Wituschek ${ }^{2} \cdot$ Mathias Bobbert $^{1} \cdot$ Gerson Meschut $^{1}$
}

Received: 15 October 2021 / Accepted: 10 January 2022 / Published online: 3 February 2022

(c) The Author(s) 2022

\begin{abstract}
By applying a variety of strategies, including both the development of new drive concepts as well as the use of lightweight constructions, it is intended to meet the climate targets set by the Paris Agreement. Multi-material design is often used when applying lightweight constructions, especially in the mobility sector. Herby, various materials with different properties are combined to well adapt the structure to the application of force in order to reduce weight. For example, this can result in the combined use of (high-strength) steel and aluminium. However, the increasing number of materials used and the number of resulting joints has led to the development of a number of different joining processes. These can only be used to a limited extent for joining multi-material joints and are usually inflexible facing changing boundary conditions. Examples of further difficulties affecting the established processes are metallurgical incompatibilities, which particularly pose difficulties for the use of thermal joining processes. A frequently used mechanical joining process is self-piercing riveting. Due to its high load-bearing capacities, a wide range of application and high process robustness it is often used when joining of dissimilar material is required. However, in case of self-piercing riveting used, the increasing number of multi-material joints and material-thickness combinations leads to the need of a large number of rivet-die-combinations to adapt the joining process to the respective joining task. Since the joining system cannot react to these changes, a tool change or an adjustment of the system is necessary, which leads to a reduction in efficiency and extended process times. To increase flexibility and process efficiency, new, versatile joining technologies are needed that can be adapted to changing boundary conditions. One possibility for this is the use of multi-range capable semi-tubular self-piercing rivets, which are inserted into the joint by using a new joining system with extended punch-sided actuator technology. The increased actuator technology enables the rivet to be set by an inner punch and subsequently to form a rivet head by embossing with an outer punch. All punch movements can be controlled independently of each other, enabling adaptive adjustment of the process parameters. Depending on the rivet geometry used, rivet head formation by the outer punch can be performed both with and without head deformation. The rivet without head deformation consists of a tubular shape with ring grooves in the rivet head area. Using the outer punch, punch-sided material is formed into the ring grooves creating an interlock in the head area of the rivet. The rivet with head deformation is designed differently. It is modified to enable subsequent forming to the respective thickness of the joint by forming the protrusion of the rivet head onto the punch-sided joining part. In the study presented here, the joining process of the versatile self-piercing riveting is presented, analysed and the property profile of the joints is determined on the basis of various material-thickness combinations. Here, both the characteristic parameters of the joints and the joint load-bearing capacities are determined. Finally the property profiles are compared with conventionally manufactured joints in order to identify potential for improvement.
\end{abstract}

Keywords Mechanical joining $\cdot$ Self-piercing riveting $\cdot$ Versatile joining $\cdot$ Joint properties $\cdot$ Joining technology

Fabian Kappe

fabian.kappe@1wf.upb.de

1 Laboratory for Material and Joining Technology (LWF), Paderborn University, Paderborn, Germany

2 Institute of Manufacturing Technology, Friedrich Alexander University Erlangen Nuremberg, Nuremberg, Germany

\section{Introduction}

Nowadays changing climate protection policies and the limitation of natural resources pose major challenges for car body development. In addition, conflicting objectives such as higher safety requirements and reduced weight to 
save pollutant emissions or extending the range of batterypowered vehicles have to be reconciled during development. This leads to an increased use of lightweight design [1]. One possible strategy is the use of multi-material structures and the associated weight reduction. In this case, different materials are combined to ensure adaptation of the structure to the application of load. However, the use of different materials constitute challenges to the required joining technology due to their different properties. Thermal joining technologies in particular reach their application limits due to the incompatibilities of the materials, which is why mechanical joining techniques are increasingly being used as they allow the joining of dissimilar materials [2].

One mechanical joining technology which is often used for this type of joining task is semi-tubular self-piercing riveting (SPR). Here, two or more sheets are joined using a rivet as auxiliary joining part. After cutting the punch-sided joining part the rivet expands in the die-sided sheet forming a mechanical interlock. A force-fit and form-fit connection is created. The process sequence can be seen in Fig. 1. This joining technology offers many advantages like high loadbearing capacities and the realisation of the joints in one single step [3].

However, changing boundary conditions such as joining a different material-thickness combination requires a change of the rivet-die combination used in order to ensure the joints quality-relevant characteristics. As the currently rigid tool-systems can not react to these changes increased process times and a loss in process efficiency results. There are several approaches to increase the flexibility of the SPRprocess. The shank volume in particular poses a problem for riveted joints. It limits the possible thickness of the joining parts. One possibility is therefore the elimination of the shank volume using a hollow rivet design [5]. Developing of stress-optimised rivets also offers an opportunity to increase the flexibility of the process by using one rivet geometry for joining different material combinations [6]. In addition to the development of new rivet geometries, a flexibilisation of the process can also be achieved by modifying the process kinematics. For example, due to a rotation of the rivet at high speed and the resulting plastification of the punch-sided joining part, semi-tubular self-piercing riveting can be used to join brittle materials [7]. Using double-sided self-piercing riveting (DSSPR) allows the formation of a planar joint by mechanical joining processes. Here, a tubular joining part is placed between the punch and the die-sided sheet which are afterwards pressed together. An interlock of the auxiliary joining part in both sheets results [8]. In other mechanical joining processes, such as self-piercing riveting with solid rivet, one possibility to increase flexibility is given by adding ring grooves in the area of the rivet shank, which allows adaptation to different material thicknesses. Mucha [9] found, that the shear joint strengths are dependent on the choice of the auxiliary joining element used. This behaviour could be related to the cylindrical shape of the joining part as well as the filling of ring grooves which differ between the universal and the special solid rivet. Through additional movement in the lower die, the required joining force in self-piercing riveting with a solid rivet were reduced by up to $30 \%$ and an increase in the joint load-bearing capacity could be achieved [10].

In order to react to changing boundary conditions like changing sheet thicknesses, there is also the possibility of increased punch-side kinematics combined with the use of multi-range capable rivets. An adaptive adjustment of the joining process to changed boundary conditions is hereby made possible. The general feasibility of this joining technology was presented using a substitute model considering the head formation in [11]. The process sequence of this versatile self-piercing riveting process (V-SPR) is divided into a setting and a forming process. For this reason, the joining system consists of an inner and an outer punch. The inner punch sets the rivet whereas the outer punch fulfils the forming process. After cutting the punch sided sheet, the rivet expands in the die-sided material forming a mechanical interlock. Subsequently, a forming process is carried out. Using the rivet without head deformation, the punch-sided sheet is formed into ring grooves. These are located in the
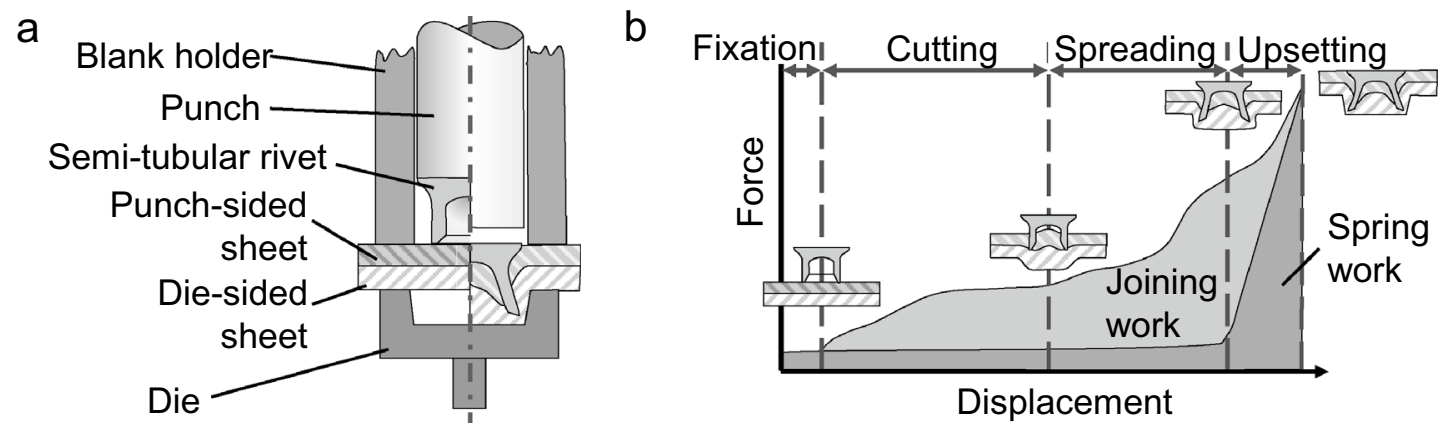

Fig. 1 Tooling for SPR (a) and process sequence for SPR as well as the exemplary joining force-displacement curve (b) according to [4] 
head area of the rivet. The embossed material creates an interlock between the punch-sided joining part and the rivet head, Fig. 2a. The protrusion of the rivet head is formed onto the punch-sided joining part, if the multi-range capable rivet with head deformation is used (see Fig. 2b). Just like the conventional SPR-process, a force-fit and form-fit connection is created when using the multi-range capable rivets.

\section{Experimental procedure}

\subsection{Materials}

In order to determine the properties of the multi-range capable semi-tubular rivets, different typical automotive materialthickness combinations are used which are typically joined using SPR. Here, the aluminium alloy EN AW-6014 temper T4 with sheet thicknesses of $1.0 \mathrm{~mm}, 1.5 \mathrm{~mm}$ and $2.0 \mathrm{~mm}$ are used. The chemical compositions and the mechanical properties of the sheet material is shown in Table 1.

The joints are joined using both conventional SPR and the newly developed V-SPR process. The conventional rivets

\section{a Rivet without head deformation}

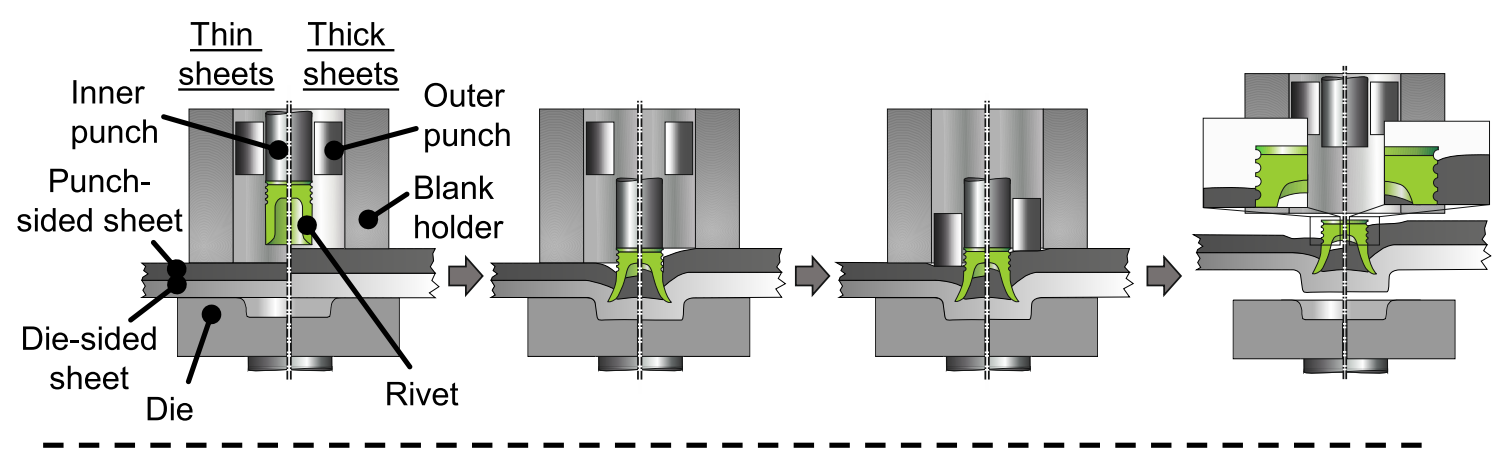

b Rivet with head deformation

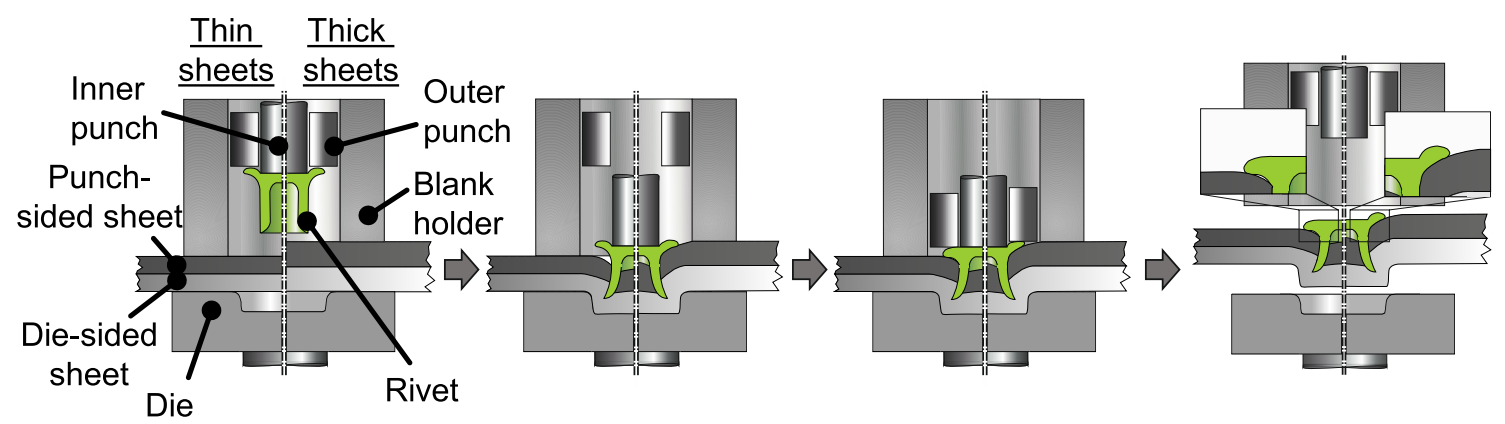

Fig. 2 Process sequence for V-SPR without head deformation (a) and with head deformation (b)

Table 1 Chemical compositions and mechanical properties of investigated material EN AW-6014 [12]

Chemical composition EN AW-6014, T4 (weight \%)

\begin{tabular}{|c|c|c|c|c|c|c|c|c|c|}
\hline & $\mathrm{Si}$ & $\mathrm{Fe}$ & $\mathrm{Cu}$ & $\mathrm{Mn}$ & $\mathrm{Mg}$ & $\mathrm{Cr}$ & $\mathrm{Zn}$ & $\mathrm{Ti}$ & V \\
\hline Min & 0.30 & & & 0.05 & 0.40 & & & & \\
\hline Max & 0.60 & 0.35 & 0.25 & 0.20 & 0.80 & 0.20 & 0.10 & 0.10 & 0.10 \\
\hline \multicolumn{10}{|c|}{ Mechanical properties EN AW-6014, T4 } \\
\hline \multicolumn{2}{|c|}{ Density $\left(\mathrm{kg} / \mathrm{m}^{3}\right)$} & \multicolumn{3}{|c|}{ Young modulus $\left(\mathrm{N} / \mathrm{mm}^{2}\right)$} & \multicolumn{2}{|c|}{ Yield stress (MPa) } & \multicolumn{2}{|c|}{ UTS (MPa) } & $\operatorname{Ag}(\%)$ \\
\hline \multicolumn{2}{|c|}{$2.7 \times 108$} & \multicolumn{3}{|c|}{70,000} & \multicolumn{2}{|l|}{130} & \multicolumn{2}{|l|}{190} & 23 \\
\hline
\end{tabular}


are made of the material 38B2. They are produced by coldforming. The multi-range capable semi-tubular rivets are made of the material $\mathrm{C} 35$. These new rivet geometries are produced by machining. To ensure comparability of the rivets, the manufacturing process is followed by a hardening process that increases the strength to $480 \mathrm{HV}$. To improve corrosion resistance and friction between the rivet and the joining parts, the rivets are ALMAC coated in a final step. The chemical compositions and the mechanical properties of the rivet materials used are shown in Table 2.

\subsection{Multi-range capable rivets}

The concepts of the required multi-range capable rivets were presented in [11]. For this study, both rivet geometries were engineered in order to join combinations with sheetthickness combinations of up to $4 \mathrm{~mm}$. In particular the rivet length plays a decisive role with regard to the formation of the interlock and the minimum die-side material thickness large degrees of deformation. Both rivet geometries and their dimensions are shown in Fig. 3.

\subsection{Joining systems}

The conventional self-piercing riveted joints are produced on a TOX TE-X joining system. This system has a servo-electric drive, which enables a maximum joining force of $80 \mathrm{kN}$. It can be controlled both by displacement and force with a joining speed of up to $200 \mathrm{~mm} / \mathrm{s}$. The new rivet geometries are applied using a specially developed joining system. The tool concept for this joining system with extended tool-actuator technology has been presented and described in [11]. This system offers an increased punch-sided tool actuator technology, which enables the joining process described above. The joining system is based on a column-guided frame and can be divided into a lower and an upper tool. The upper tool contains both the outer and the inner punch as well as a

Table 2 Chemical compositions and mechanical properties of rivet material 38B2 and C35 [13]

Chemical composition 38B2 (weight \%)

\begin{tabular}{lllllllll}
\hline & $\mathrm{Si}$ & $\mathrm{C}$ & $\mathrm{Cu}$ & $\mathrm{Mn}$ & $\mathrm{P}$ & $\mathrm{S}$ & $\mathrm{Cr}$ & $\mathrm{Mo}$ \\
\hline Min & & 0.35 & & 0.60 & & & & \\
Max & 0.3 & 0.40 & 0.25 & 0.90 & 0.025 & 0.025 & 0.3 & - \\
\hline
\end{tabular}

Mechanical properties 38B2

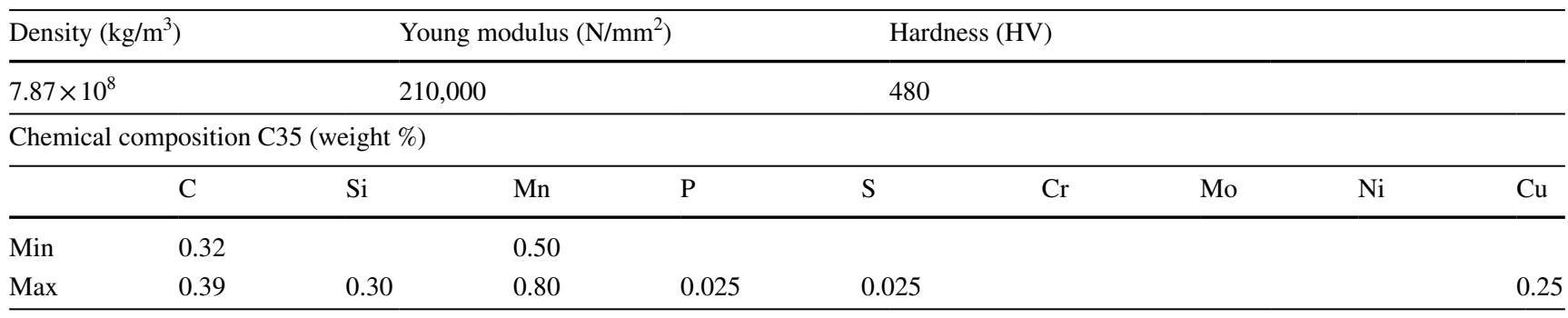

Mechanical properties C35

\begin{tabular}{lll}
\hline Density $\left(\mathrm{kg} / \mathrm{m}^{3}\right)$ & Young modulus $\left(\mathrm{N} / \mathrm{mm}^{2}\right)$ & Hardness $(\mathrm{HV})$ \\
\hline $7.87 \times 10^{8}$ & 210,000 & 480 \\
\hline
\end{tabular}

[14]. A great rivet length increases the interlock. At the same time, the minimum die-side material thickness is reduced. As the rivet without head deformation can penetrate deeper into the sheets, its length was set to $4.8 \mathrm{~mm}$. Especially with this rivet geometry, the shank volume limits the maximum possible sheet thickness as it is formed quite low. The rivet length of the rivet with head deformation was designed to $5.4 \mathrm{~mm}$, since here the formation of the rivet head after setting must be located above the sheets and deep penetration is therefore not possible. However, a too large distance between the rivet head protrusion and the punch-sided sheet could lead to cracks in the rivet head due to the resulting pneumatically blank holder. The motions of the punches are all realised using servo-electric drives. Using a compact electromechanical actuator from TOX ${ }^{\circledR}$ PRESSOTECHNIK GmbH \& Co. KG, the inner punch movement is realised whereas a driven cross-beam causes the outer punch to move. Both punch movements can be performed with joining forces of up to $80 \mathrm{kN}$ and setting speeds of up to $80 \mathrm{~mm} / \mathrm{s}$. The pneumatic cylinder of the blank holder, which is coupled to the inner punch enables a blank holder force of up to $8 \mathrm{kN}$. The lower tool contains the die assembly, which is mounted on a cross table to ensure axial alignment of the die and the punches. The 
Fig. 3 Developed rivet geometries without head deformation (a) and with rivet head deformation (b) a Rivet without head deformation

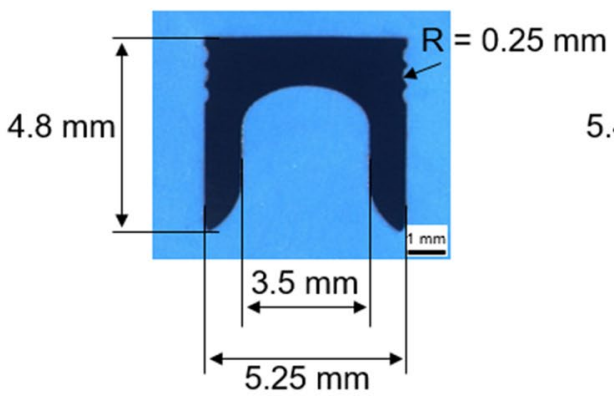

b Rivet with head deformation

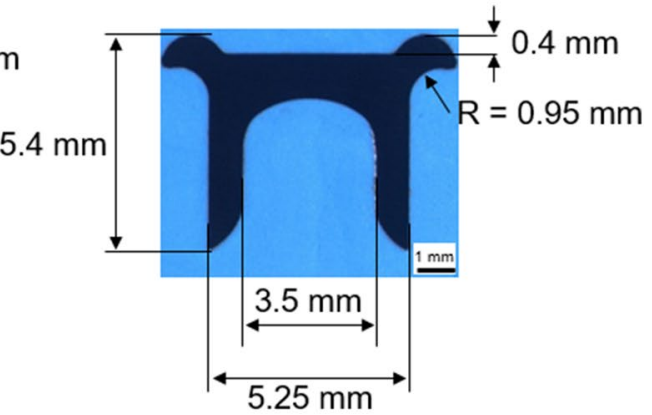

Tolerances according to DIN ISO 2768 - $f$

\begin{tabular}{|c|c|c|c|}
\hline & Type & iunner & Drives \\
\hline & TOX® TE-X & & Servo-electric \\
\hline & Drives & & Nominal force punches \\
\hline & Servo-electric & & $80 \mathrm{kN}$ \\
\hline & Nominal force punches & & Drive (blank holder) \\
\hline & $80 \mathrm{kN}$ & & Pneumatic \\
\hline & Max. joining speed & & Blank holder force \\
\hline & $200 \mathrm{~mm} / \mathrm{s}$ & & $8 \mathrm{kN}$ \\
\hline & Measurement & 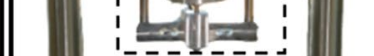 & Max. joining speed \\
\hline-8 & Force and displacement & & $80 \mathrm{~mm} / \mathrm{s}$ \\
\hline $6 \square$ & Accuracy & 1 & Measurement \\
\hline 5 i. & $< \pm 0.5 \%$ nominal force & Lower tool & Force and displacement \\
\hline
\end{tabular}

Fig. 4 Joining systems used; left: TOX-TE-X to process the conventional self-piercing rivets, right: developed joining system with extended punch-sided tool actuator technology to process the versatile self-piercing rivets

main advantage of this joining system set up is the possibility to carry out the two punch movements completely independently, allowing free parameterisation of the force and displacement profiles of the process. The characteristics of the two joining systems are shown in Fig. 4.

\subsection{Evaluation of the joint}

For the evaluation of the joint quality of the newly developed V-SPR joining process, the introduction of new, extended quality-relevant parameters for both the rivet with and without head deformation is required (Fig. 5). In the case of conventional self-piercing riveted joints, it is particularly important to consider the interlock as well as the minimum die-side material thickness and the rivet head position to assess the joint quality. These characteristic values are also considered for the quality evaluation of the newly developed rivets. However, they are partially measured slightly differently, as described below. The interlock (f), which is particularly decisive for the loadbearing capacity, is determined between the rivet foot and the die-sided sheet. For this type of rivet joint, a minimum value of $0.12 \mathrm{~mm}$ is set according to common industry standards. The smallest distance between the foot of the rivet and the outside of the die-side joining part is determined as the minimum die-side material thickness $\left(\mathrm{t}_{\mathrm{r}}\right)$. In order to avoid weakening of the die-sided joining part, a minimum distance of $0.15 \mathrm{~mm}$ is specified according to common industry standards. The rivet head position $\left(\mathrm{p}_{\mathrm{h}}\right)$, which is measured as the distance between the joining surface of the rivet, on which the inner punch acts when setting the connection, and the surface of the punch-sided sheet, is also included as an evaluation variable. In the case of joints without head deformation, the embossing depth of the outer punch $\left(h_{d}\right)$ is additionally measured. The 


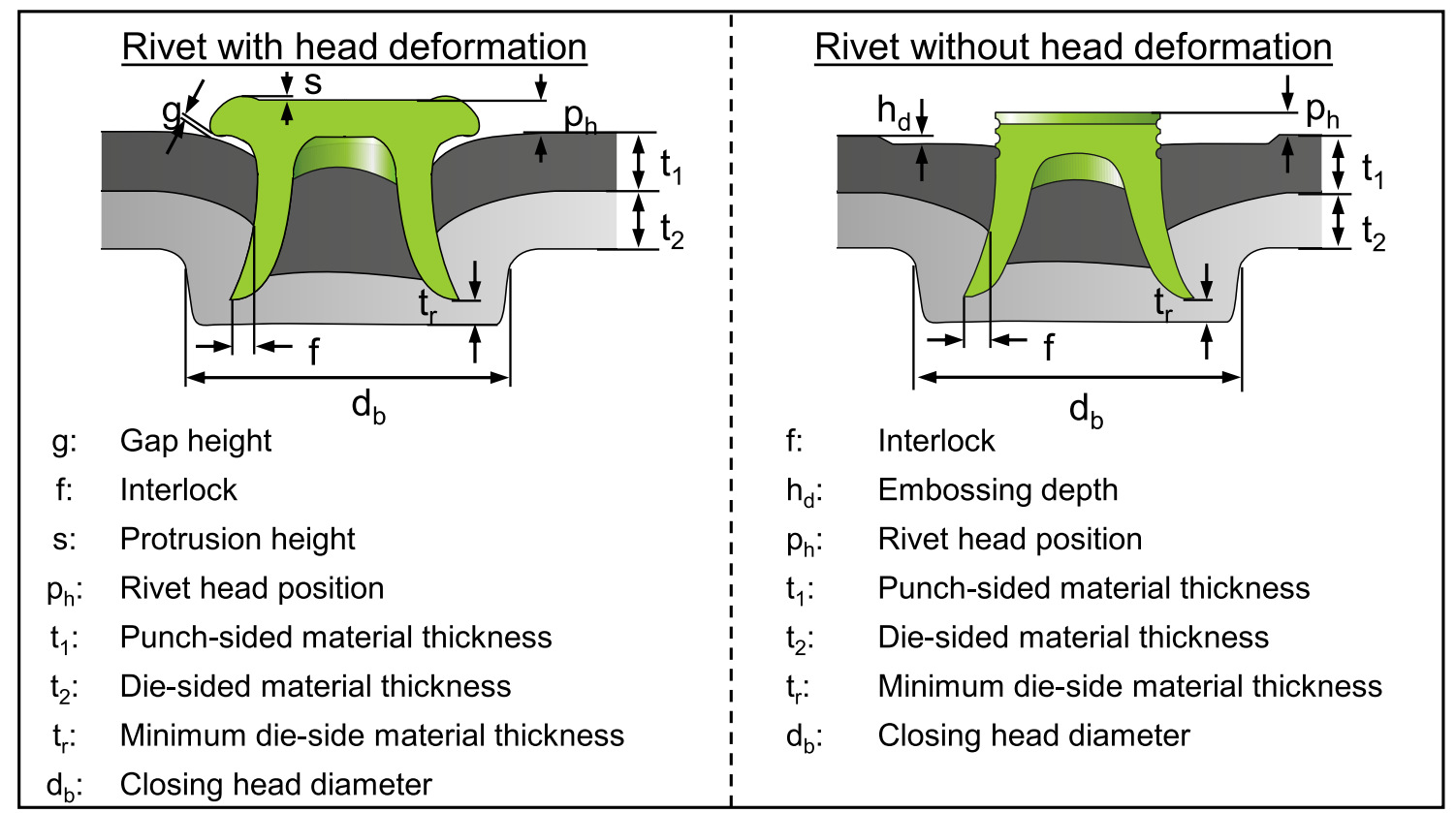

Fig. 5 Determined quality relevant parameters in order to evaluate the joint quality for the rivet with head deformation (left) and without head deformation (right)

embossing depth allows conclusions to be drawn about the forming behaviour of the punch-sided joining part and thus about the filling of the ring groove in the rivet head area, which is used as a further variable. In addition, a large embossing depth and the resulting notch may have a negative influence on the joint load-bearing capacity, as this creates a potential predetermined fracture location. Especially, the ring groove filling and the interlock formation on the rivet head side resulting from the penetration of the punch-sided joining part into the ring grooves are expected to be decisive for the joint load-bearing capacity under normal load. The requirements for the ring groove filling are comparable to that of a solid self-piercing riveting joint. As a measure for the cavity filling of the die, the closing head diameter can also be determined. When evaluating the riveting process with head deformation, the closing head diameter can also be used to identify cavity filling of the die. Using this type of rivet head formation, the gap height $(\mathrm{g})$ between the protrusion of the rivet and the surface of the punch-sided joining part must be determined. Gaps in this area of the joint must be avoided in order to avoid a possibly negative influence on the joint's load-bearing capacity and to prevent the potential infiltration of fluids into the joint. Deep penetration of the protrusion into the sheet on the punch side should also be documented when assessing the connection. A parameter that may provide information on the residual stresses within the set rivet is the protrusion height (s). This results from the distance between the upper edge of the protrusion and the joining surface of the rivet. Both the gap height and the protrusion height can take on negative values.

\subsection{Determination of the load-bearing capacity}

Shear tensile tests and cross tensile tests are carried out to determine the joint load-bearing capacity. The dimensions of the specimens as well as the execution of the investigations are standardised according to the instruction sheet DVS/EFB Merkblatt 3480-1 [15]. For quasistatic shear tensile test, overlapped single point shear test specimens are used. For this purpose, two sheet metals with the dimensions $45 \mathrm{~mm} \times 105 \mathrm{~mm}$ are joined with an overlap of $\mathrm{l}_{\ddot{\mathrm{U}}}=16 \mathrm{~mm}$. The joint is located in the geometric centre of the overlap. The free clamping length is set to $l_{F}=95 \mathrm{~mm}$. The specimens are tested to failure and evaluated based on the failure pattern and for example the maximum force. For the cross tensile test, two crosswise overlapped blanks with dimensions of $50 \mathrm{~mm} \times 150 \mathrm{~mm}$ are jointed whereas the jointing point is again placed in the geometric centre of the overlap. To enable the specimen to be inserted in the corresponding clamping device, holes are created on the outer sides of each sheet. For this reason, the free clamping length $l_{F}$ is significantly lower. The evaluation of cross tensile specimen is carried out analogously to the shear tensile test described above. The dimensions of both specimen geometries are shown in Fig. 6. 


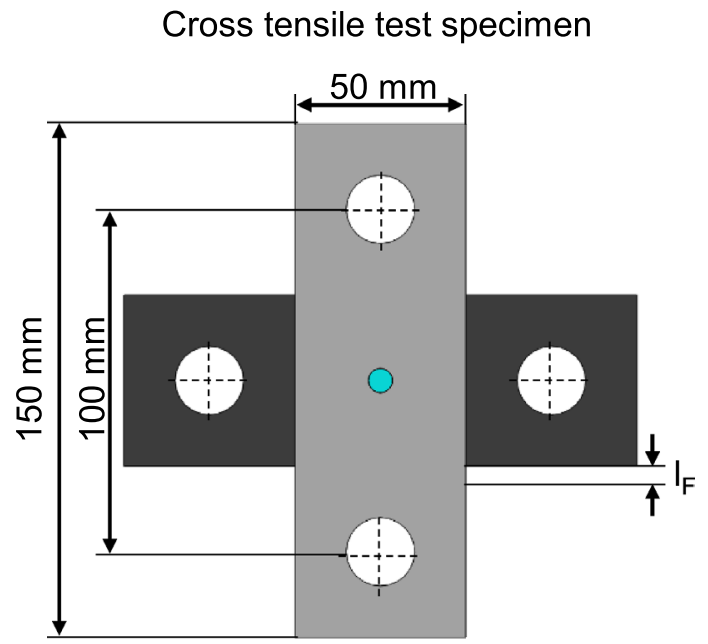

Shear tensile test specimen

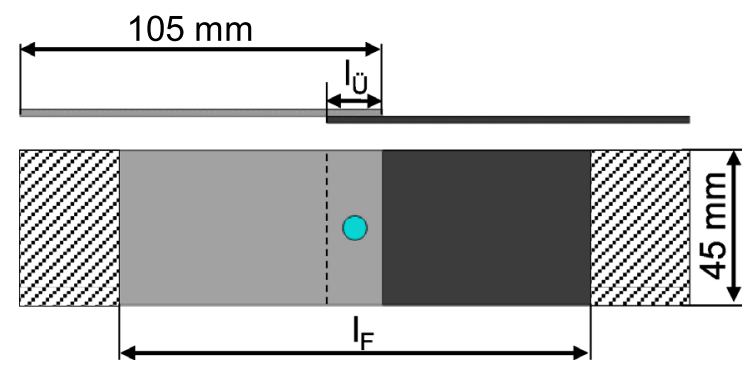

Fig. 6 Schematic illustration of the specimen geometries; left: cross tensile test specimen, right: shear tensile test specimen

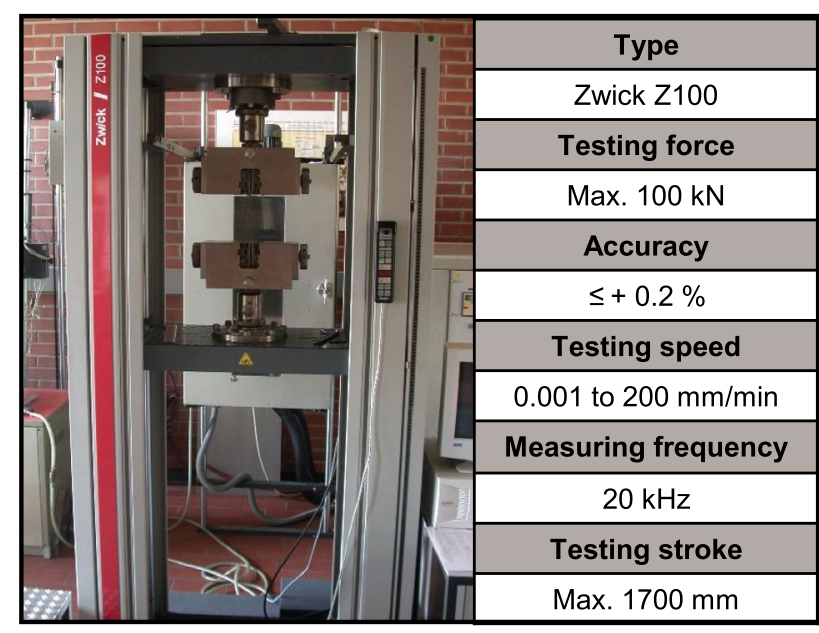

Fig. 7 Universal testing machine Zwick Z100 and technical data

The two specimen geometries were tested using a universal testing machine manufactured by Zwick (see Fig. 7). This machine has a force range of up to $100 \mathrm{kN}$ and is equipped with an integrated force-displacement measurement system. This is used for the crosshead tensile specimens. For the shear tensile tests, a local displacement measurement system using a sensor arm extensometer is used. Both tests were displacement-controlled at a test speed of $10 \mathrm{~mm} / \mathrm{min}$.

\section{Results and discussion}

In order to determine the properties of the multi-range capable SPR riveted joints experimental joining tests of different material-thickness combinations were carried out (see Table 3). In order to analyse the feasibility of the multi-range
Table 3 Material-thickness combinations used to determine the properties of the developed multi-range capable rivets

\begin{tabular}{lllll}
\hline & $\begin{array}{l}\text { Punch-sided } \\
\text { sheet }\end{array}$ & $\begin{array}{l}\text { Thick- } \\
\text { ness } \\
(\mathrm{mm})\end{array}$ & $\begin{array}{l}\text { Die-sided } \\
\text { sheet }\end{array}$ & $\begin{array}{l}\text { Thick- } \\
\text { ness } \\
(\mathrm{mm})\end{array}$ \\
\hline Combination A & EN AW-6014 & 1.0 & EN AW-6014 & 2.0 \\
Combination B & EN AW-6014 & 1.5 & EN AW-6014 & 2.0 \\
Combination C & EN AW-6014 & 2.0 & EN AW-6014 & 2.0 \\
\hline
\end{tabular}

capability, only the thickness of the punch-sided sheet was varied. The die-sided sheet thickness was kept constant in all combinations in order to exclude mutually influencing effects. In addition, all joints fulfil the preferred joining direction of thin to thick, which is desired for semi-tubular self-piercing riveting. Process parameters were elaborated for each combination and the joints were joined. The parameters of the process refer to both the inner and outer punch strokes and the die geometry used. Although the thickness of the material varies considerably, only one die diameter $(9.5 \mathrm{~mm})$ and one die depth $(1.4 \mathrm{~mm})$ was required in order to create all combinations. Subsequently, macroscopic crosssections were prepared and analysed according to the above defined quality-relevant parameters.

\subsection{Joint formation}

\subsubsection{Without rivet head deformation}

The macroscopic analysis (Fig. 8) of the joints without rivet head deformation is carried out on the basis of the interlock (f), the embossing depth $\left(h_{d}\right)$, the rivet head position $\left(p_{h}\right)$, the minimum die-side material thickness $\left(t_{r}\right)$ and the closing head diameter $\left(\mathrm{d}_{\mathrm{b}}\right)$. In addition, the ring groove filling 


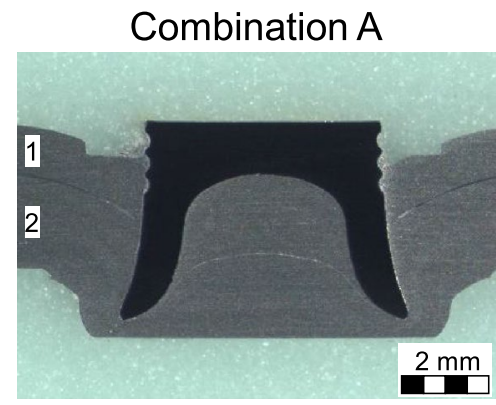

1: EN AW-6014 T4 $\mathrm{t}=1.0 \mathrm{~mm}$

2: $\mathrm{EN} \mathrm{AW}-6014 \mathrm{~T} 4 \mathrm{t}=2.0 \mathrm{~mm}$

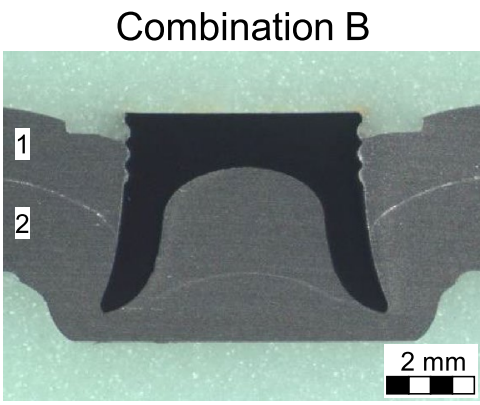

1: EN AW-6014 T4 t $=1.5 \mathrm{~mm}$

2: EN AW-6014 T4 t $=2.0 \mathrm{~mm}$

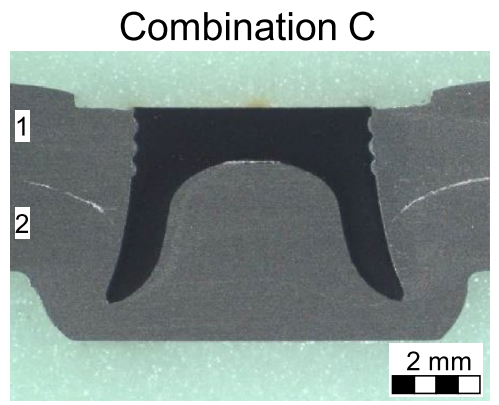

1: $\mathrm{EN} \mathrm{AW}-6014 \mathrm{~T} 4 \mathrm{t}=2.0 \mathrm{~mm}$

2: $\mathrm{EN} \mathrm{AW}-6014 \mathrm{~T} 4 \mathrm{t}=2.0 \mathrm{~mm}$

Fig. 8 Joints of the rivet without head deformation (EN AW-6014 T4 t=1.0 mm in EN AW-6014 T4 t=2.0 mm [A]; EN AW-6014 T4 $\mathrm{t}=1.5 \mathrm{~mm}$ in EN AW-6014 T4 t=2.0 mm [B]; EN AW-6014 T4 t=2.0 mm in EN AW-6014 T4 t=2.0 mm [C])

is also taken into account as this might be decisive for the load-bearing capacity of the joint. All joints meet the set minimum quality-relevant characteristics for all parameters. The minimum die-side material thickness and the interlock are within an acceptable range. Furthermore, it can be proven that the punch-sided material has been formed into the respective ring grooves by the outer punch. In combination $\mathrm{A}$, one ring groove is filled completely and a second one is filled halfway. Two ring grooves are filled in combination B with a filling of approximately $80 \%$ in each case. All three ring grooves are entirely filled using the thickest combination $\mathrm{C}$. The analysis shows, that an increase in interlock is accompanied by a decrease of the sheet thickness combination. However, this also results in an decrease of the minimum die-side material thickness. This relationship results from the lower penetration of the rivet into the diesided sheet with increasing material thickness. Although the rivet penetrates deeper into the punch-sided material combination, the rivet shank volume is completely filled at an early stage, especially with increasing material thickness. As a result, the further material is predominantly displaced without contributing to the expansion of the rivet. Therefore, the resulting interlock is less pronounced. Regardless of the sheet thickness combination, the embossing depth remains almost constant for all joints. An increase of the embossing depth might not contribute to a significant improvement of the joint, as this would lead to a higher stress concentration in the forming zone of the punch-sided material which is formed into the ring grooves. This might causes pre-damage, which can result in shearing of the filled ring groove during the joining process. In addition, a large embossing depth might have a negative influence on the joint load bearing capacity due to the resulting notch effect.

\subsubsection{With rivet head deformation}

The evaluation of the riveting process with head deformation is carried out using the interlock (f), the gap height
Combination A

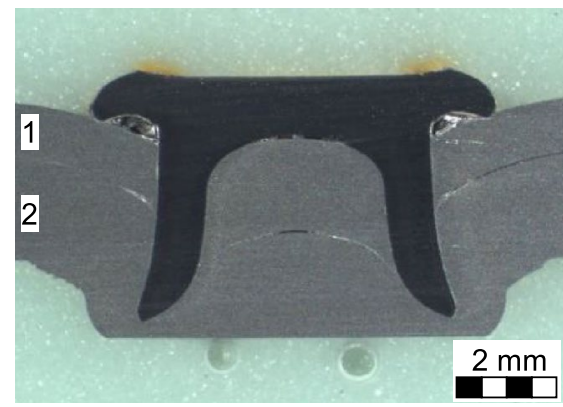

1: EN AW-6014 T4 $\mathrm{t}=1.0 \mathrm{~mm}$

2: EN AW-6014 T4 t $=2.0 \mathrm{~mm}$
Combination B

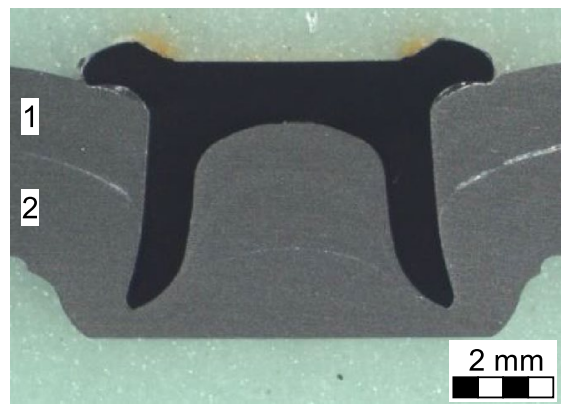

1: $\mathrm{EN} \mathrm{AW-6014} \mathrm{T4} \mathrm{t}=1.5 \mathrm{~mm}$

2: $\mathrm{EN} \mathrm{AW-6014} \mathrm{T4} \mathrm{t}=2.0 \mathrm{~mm}$
Combination $\mathrm{C}$

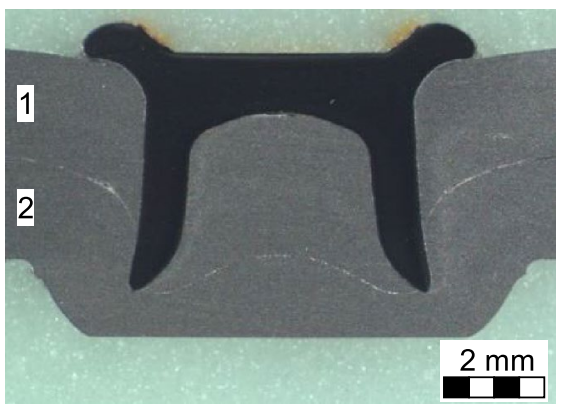

1: $\mathrm{EN} \mathrm{AW-6014} \mathrm{T4} \mathrm{t}=2.0 \mathrm{~mm}$

2: $\mathrm{EN} \mathrm{AW}-6014 \mathrm{~T} 4 \mathrm{t}=2.0 \mathrm{~mm}$

Fig. 9 Joints of the rivet with head deformation (EN AW-6014 T4 t=1.0 mm in EN AW-6014 T4 t=2.0 mm [A]; EN AW-6014 T4 t=1.5 mm in EN AW-6014 T4 $\mathrm{t}=2.0 \mathrm{~mm}[\mathrm{~B}]$; EN AW-6014 T4 t=2.0 mm in EN AW-6014 T4 t=2.0 mm [C]) 
$(\mathrm{g})$, the protrusion height $(\mathrm{s})$, the rivet head position $\left(\mathrm{p}_{\mathrm{h}}\right)$, the minimum die-side material thickness $\left(\mathrm{t}_{\mathrm{r}}\right)$ and the closing head diameter $\left(\mathrm{d}_{\mathrm{b}}\right)$ as quality-relevant characteristics. Again, all joints meet the defined parameters. Using this rivet geometry all three combinations are able to be joined (Fig. 9). Principally, no defects such as cracks in the joining parts or the rivet can be detected. The reduction of the sheet thickness combination is also accompanied by an increase of the interlock. At the same time, this leads to a reduction of the minimum die-side material thickness. This correlation is significantly higher compared to the rivet without head deformation shown above despite the greater rivet length. For the thickest sheet metal joint (combination C), an interlock of only $0.15 \mathrm{~mm}$ is achieved. In none of the joints can a gap height be determined between the protrusion of the rivet head and the punch-side joint part. In addition, the protrusion height increases with the increase in sheet thickness, whereas the rivet head position is reduced. This shows that less forming of the protrusion of the rivet head is needed as the sheet thickness increases. For example, combination $\mathrm{C}$ is created without embossing. Due to the deep penetration of the rivet into the parts to be joined and the resulting bending up of the rivet head protrusion, the protrusion height even increases to a value that is greater than the initial height (initial protrusion height $0.4 \mathrm{~mm}$ ). When using smaller sheet thickness combinations after forming the rivet head protrusion, a cavity is created between the rivet head and the punch-sided joining part. However, as the embossing of the protrusion is sufficiently large no gap height can be detected. Accordingly, no negative influences on the joint formation are to be expected. Nevertheless, the air inclusions may cause problems in following process steps such as CDP coating. Further investigations need to focus on reducing these cavities.

\subsection{Shear-load}

\subsubsection{Without rivet head deformation}

Figure 10 shows the test force-displacement curves of the V-SPR process without rivet head deformation under shear load. All joints show correspondingly high load-bearing capacities. In addition, only a small dispersion between the samples of a series is recognisable. The highest maximum force is reached by combination $\mathrm{C}$ with approximately 4 $\mathrm{kN}$. All joints fail by unbuttoning of the punch-sided sheet. In addition, especially with combination $\mathrm{A}$ and $\mathrm{B}$, a plastic deformation of the punch-sided joining part occurs. The joint load-bearing capacity of this rivet geometry is thus significantly influenced by the interlock in the head area of

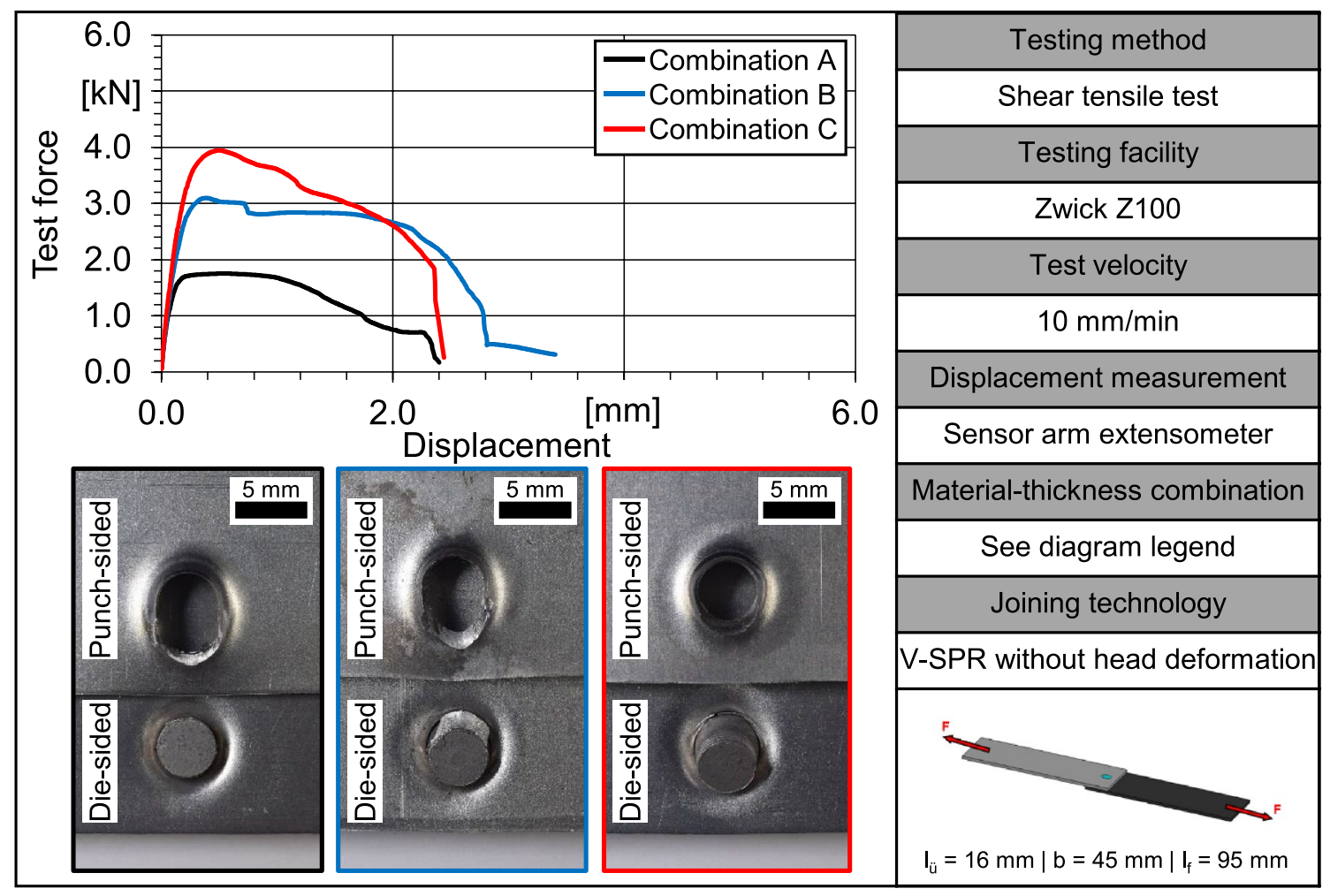

Fig. 10 Test force-displacement curves for the V-SPR riveted joints without head deformation under shear load and compilation of exemplary fracture patterns 
the rivet and the filling of the annular ring groove. The test force-displacement curves also illustrate a stepwise failure of the joints. This results from the number of filled ring grooves (see Fig. 8). This behaviour is particularly evident in combination $\mathrm{B}$ and $\mathrm{C}$ in the upper part of the curve. The first drop in force is caused by shearing of the first ring groove. Subsequently, a short holding phase occurs followed by the further failure of the joint.

\subsubsection{With rivet head deformation}

If a rivet with rivet head deformation is used satisfactory strength levels are achieved as well (see Fig. 11). Maximum forces between 3.5 and $5.5 \mathrm{kN}$ are provided for all combinations. In combination A, a failure of the joining part occurs. For this reason, the quality relevant parameters minimum die-side material thickness and gap height are correspondingly important in the assessment of the joint. A thin minimum die-side material thickness might lead to a weakening of the die sided sheet and thus to premature failure. A weakening of the punch-sided sheet could be caused by excessive embossing of the rivet, which can be evaluated using the gap height. In combinations $\mathrm{B}$ and $\mathrm{C}$, the rivet unbuttons. The difference between the two combinations is the plastic work absorbed. Due to the larger interlock found in combination B compared to combination $\mathrm{C}$, the joint fails at a greater displacement. In addition, a stronger plastic deformation of the punch-sided sheet is recognisable, whereby an increase of the energy absorption of about $50 \%$ is achieved. Again, only a small scatter between the samples of a series is recognisable.

\subsection{Cross tensile load}

\subsubsection{Without rivet head deformation}

The rivet geometry without head deformation possesses a low load-bearing capacity under cross tension load (see Fig. 12). Combination A fails at $600 \mathrm{~N}$, offering low handling strength. The maximum force is reached with combination $\mathrm{C}$ at $1.8 \mathrm{kN}$. In all combinations, the punchsided sheet fails by unbuttoning. A staged failure, which was detected in shear tensile test, cannot be observed. The sheets do not show any plastic deformation, which indicates that the filled ring grooves are sheared off. The load-bearing capacity is therefore significantly dependent on the number of ring grooves filled as well as the degree of filling. Filling several ring grooves increases the surface area that transmits the load. Accordingly, the load is distributed over a larger cross-section, which reduces the

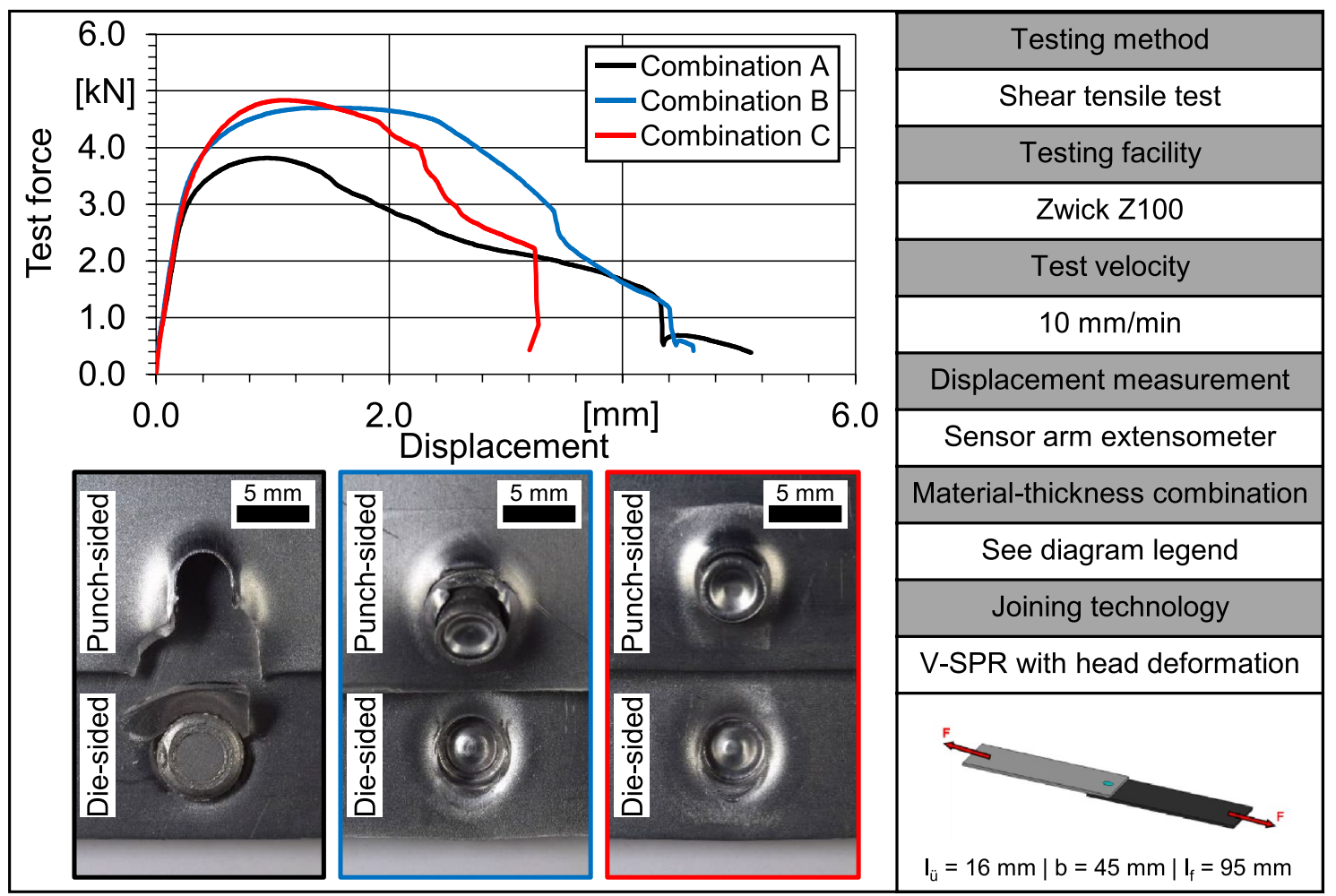

Fig. 11 Test force-displacement curves for the V-SPR riveted joints with head deformation under shear load and compilation of exemplary fracture patterns 


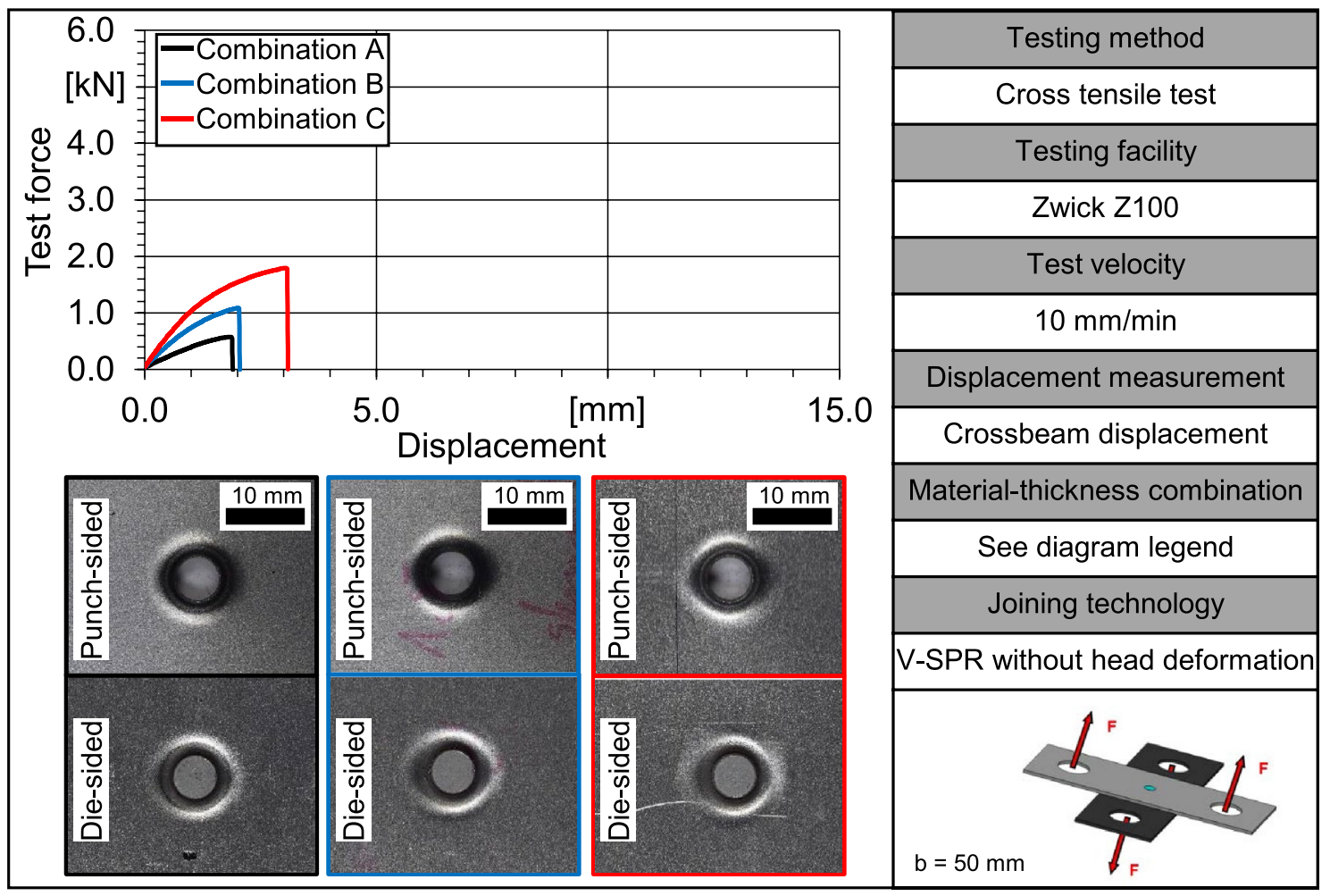

Fig. 12 Test force-displacement curves for the V-SPR riveted joints without head deformation under cross tensile load and compilation of exemplary fracture patterns

stress occurring within the rivet head area. The joint can therefore bear a greater load and a subsequent failure of the joint as well as increased energy absorption occurs. This relationship can also be proven by the calculation of the shear stress at failure of the joint, which is at a comparable level between 41 and $45 \mathrm{~N} / \mathrm{mm}^{2}$ for all joints.

\subsubsection{With head deformation}

Figure 13 shows the test force-displacement curves of the V-SPR process with head deformation under cross tensile load. All combinations demonstrate an excellent level of strength. This refers to both the maximum force achieved and the displacement at failure. Combination $\mathrm{C}$ offers the lowest load-bearing capacity with a maximum force of approx. $2 \mathrm{kN}$. This combination fails after a displacement of $5 \mathrm{~mm}$ due to the rivet unbuttoning. The failure can again be explained by the small interlock. An increase of the interlock would positively influence the joint load-bearing capacity. Combinations $\mathrm{A}$ and $\mathrm{B}$ fail at comparable displacements from 11 to $13 \mathrm{~mm}$. The later failure leads to a high energy absorption, which is also visible in the plastic deformation of the parts to be joined. For combination A failure of the thin punch-sided sheet occurs, which is initiated in the area of the punched slug. Combinations B fails due to unbottening.
However, the tests carried out also show that there is a large deviation in the force-displacement curves, especially with Combination $\mathrm{C}$. The cause is suspected to be varying expansion of the rivet and, for this reason, fluctuating interlock formation as a result of the large thickness of the punchsided sheet. In addition, combination B shows a greater dispersion than the joints of combination A.

\subsection{Comparison of the load-bearing capacities}

The analysis of the load bearing behaviour listed above shows that both rivet geometries offer great potential with regard to sheet thickness variations. Various sheetthickness combinations can be joined with only one rivet geometry and one die geometry required. To evaluate these results, the load-bearing behaviour under shear- and cross tensile load is compared with conventionally created joints. For this purpose, these were sampled according to the quality-relevant parameters for the interlock (f), the minimum die-side material thickness $\left(\mathrm{t}_{\mathrm{r}}\right)$ and the rivet head position $\left(\mathrm{p}_{\mathrm{h}}\right)$ according to industrial standards (see Table 4). To create the joints using the conventional SPR, 3 rivet geometries and 3 different dies were required.

When using conventional self-piercing rivets, larger interlocks are tendentially achieved. Here, the joints partly 


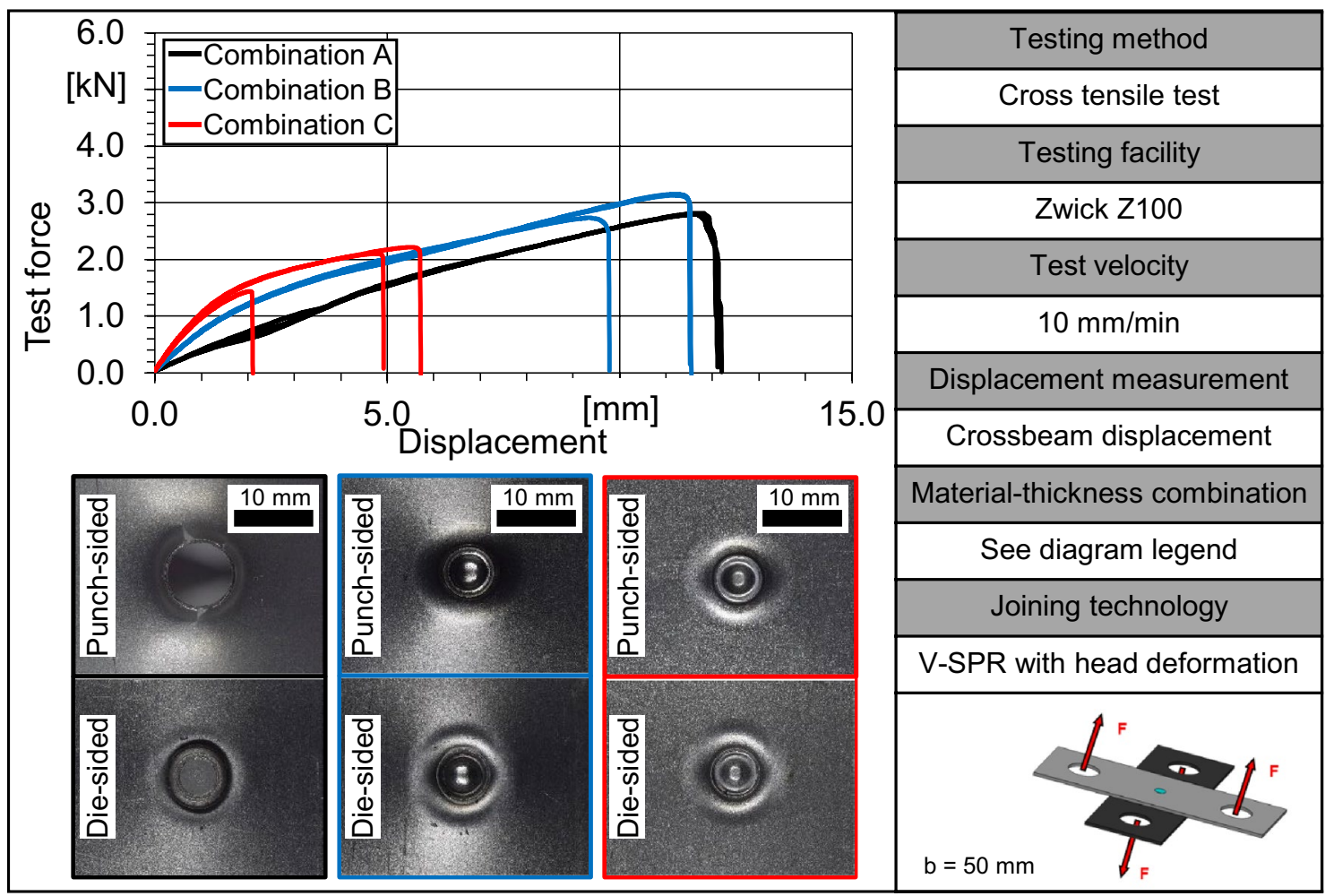

Fig. 13 Test force-displacement curves for the V-SPR riveted joints with head deformation under cross tensile load and compilation of exemplary fracture patterns

Table 4 Summary of the quality-relevant characteristics for joints $\mathrm{A}$ to $\mathrm{C}$ for conventional SPR (left), V-SPR without head deformation (middle) and V-SPR with head deformation (right)

\begin{tabular}{|c|c|c|c|c|c|c|c|c|c|}
\hline & \multicolumn{3}{|l|}{ SPR } & \multicolumn{3}{|c|}{$\begin{array}{l}\text { V-SPR (without head defor- } \\
\text { mation) }\end{array}$} & \multicolumn{3}{|c|}{$\begin{array}{l}\text { V-SPR (with head } \\
\text { deformation, }\end{array}$} \\
\hline & $\mathrm{f}$ & $\mathrm{t}_{\mathrm{r}}$ & $\mathrm{p}_{\mathrm{h}}$ & $\mathrm{f}$ & $\mathrm{t}_{\mathrm{r}}$ & $\mathrm{p}_{\mathrm{h}}$ & $\mathrm{f}$ & $\mathrm{t}_{\mathrm{r}}$ & $\mathrm{p}_{\mathrm{h}}$ \\
\hline Combination A & 0.52 & 0.15 & 0.04 & 0.45 & 0.37 & 0.02 & 0.38 & 0.32 & 0.35 \\
\hline Combination B & 0.45 & 0.25 & 0.05 & 0.38 & 0.60 & -0.26 & 0.28 & 0.53 & 0.02 \\
\hline Combination $\mathrm{C}$ & 0.35 & 0.18 & 0.11 & 0.35 & 0.79 & -0.58 & 0.15 & 0.82 & -0.17 \\
\hline
\end{tabular}

have a twice as large interlock as the joints joined with multi-range capable rivets. However, the minimum dieside material thicknesses are significantly lower, as the rivet penetrates deeper into the sheets. The comparison of the load-bearing capacities is carried out on the basis of the maximum force as well as the possible energy absorption of the joint. Both parameters provide a deep insight into the joints and thus enable the derivation of improvement potentials for the new rivet geometries.

\subsubsection{Shear load}

Figure 14 shows the comparison of the maximum forces under shear tensile load. Both the conventional and the versatile self-piercing riveting show correspondingly high load-bearing capacities. The rivet geometries with head deformation achieve higher maximum forces for all joints, compared to the rivet geometries without head deformation. Reasons for this are the types of failure described above and the design of the rivet head. The load-bearing capacity of the rivet variant without head deformation is largely determined by the degree filling of the ring grooves as well as the number of ring grooves filled. This is also shown by a linear increase in the maximum force with an increase in the thickness of the punch-sided joining part. The greater thickness leads to more annular grooves are filled. This increases the cross-section area of the interlock, which is formed between the rivet head and the punch-sided joining part. The occurring stresses can thus be reduced in accordance to the larger surface area. However, the investigation also indicates that the increase in the maximum possible force decreases with 
Fig. 14 Comparison of the achieved maximum forces under shear load for the combinations A to $\mathrm{C}$ using conventional SPR, V-SPR without head deformation and V-SPR with head deformation

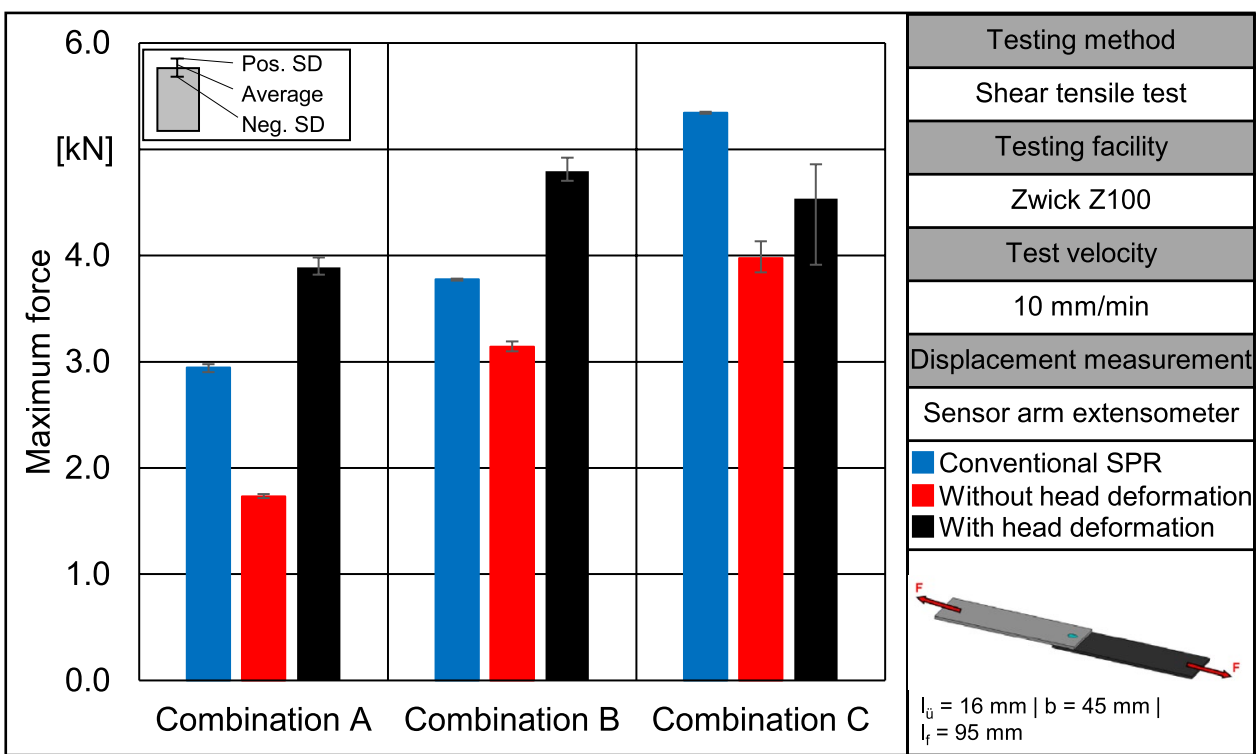

greater sheet thickness used. It can therefore be assumed that the increase in the number of ring grooves filled does not result in a constant improvement in the load-bearing capacity. The conventional rivet geometries show consistently high maximum forces between 3.0 and $5.5 \mathrm{kN}$. With increasing sheet thickness, there is also a constant increase in the maximum force achieved due to the increasing stiffness of the joining partners. In two of the three combinations, the values of the rivet with rivet head deformation are still above the SPR joint although a smaller interlock is formed in each case. This demonstrates that the interaction between the rivet head formation and the interlock achieved has a decisive influence on the maximum force achieved. However, if the undercut is getting close to the minimum defined value (Combination $\mathrm{C}$ ), a sharp drop in force and premature failure results.

The energy absorption (Fig. 15) also shows large differences between the two multi-range capable rivet geometries. Again, the values achieved for the rivets with head deformation are above those without head deformation. However, the differences are more pronounced here. The conventional rivets as well as the rivets with rivet head deformation achieve at least an energy absorption of $10 \mathrm{~J}$. The maximum energy absorption for the conventional rivets occurs at Combination $\mathrm{C}$ with a maximum of approx. $25 \mathrm{~J}$. Here, the variant with rivet head deformation achieves the lowest value of $10 \mathrm{~J}$ in comparison. This behaviour is due to the interlock formed. In this combination, the interlock of the conventional rivet is twice as high as in the case of the rivet with
Fig. 15 Comparison of the achieved energy absorption under shear load for the combinations $\mathrm{A}$ to $\mathrm{C}$ using conventional SPR, V-SPR without head deformation and V-SPR with head deformation

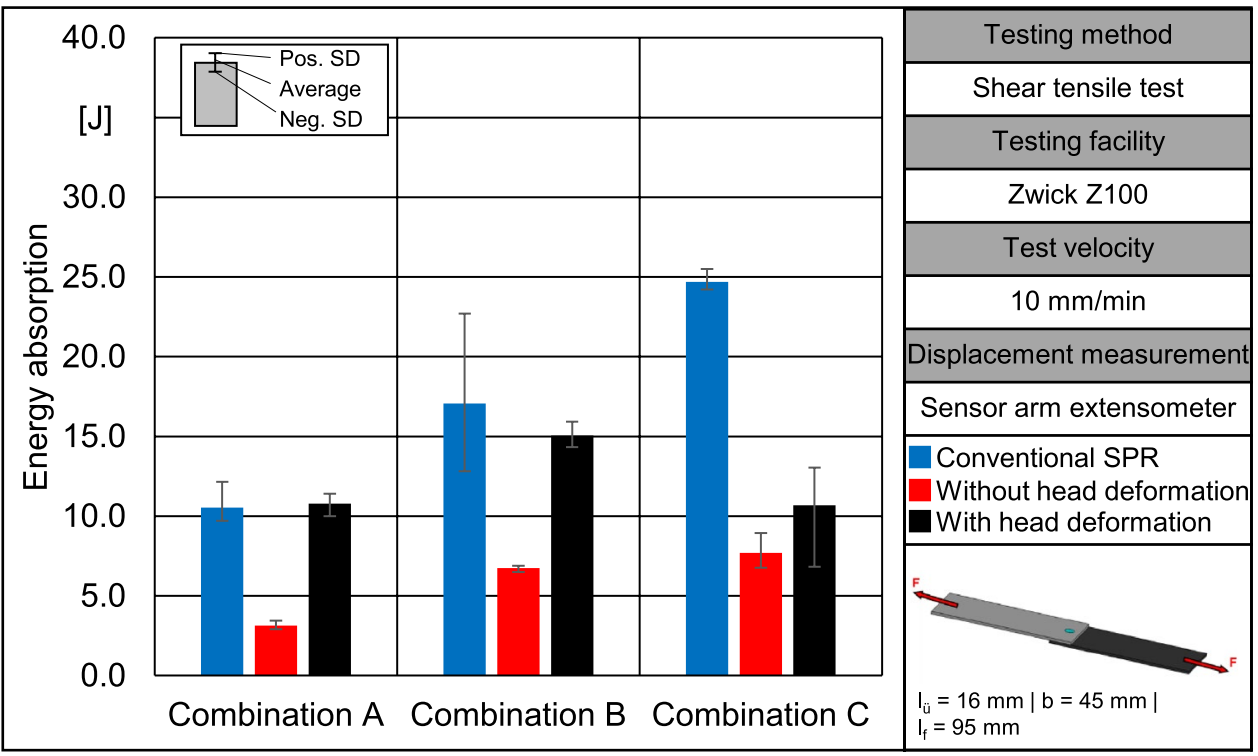


head deformation. Due to the large sheet thickness of both joining partners and the resulting stiffness, the formation of a small interlock leads to an early loosening of the joint due to unbottening. In addition, it is shown that a large interlock does not lead automatically to a high energy absorption. The value for the interlock of the rivet without head deformation is on a level with the conventional rivet, however, a high energy absorption does not result from this as the ring groove filling fails. Initially, there is a pronounced increase in the force. However, as can be seen in the fracture pattern above, the increasing force leads to a demoulding of the rivet element from the die-sided joining part. This leads to greater concentration of load within the interlock in the rivet head area. By increasing load, the joint loses within the head area and finally fails. The evaluation of the energy absorption also shows that the conventional rivets achieve higher values than the new rivet geometries with rivet head deformation, although these achieve greater maximum forces. The failure of the joints occurs later when conventional rivets are used, which enables the joints to absorb more energy.

\subsubsection{Cross tensile load}

Under cross tensile load, the maximum forces of the conventional rivet and the multi-range capable rivet with head deformation are consistently at a comparable level (see Fig. 16). Only in combination $C$ the conventional rivet achieves twice as high maximum forces. This is again caused by the significantly larger interlock. Due to the unbuttoning of the joints at failure, a negative influence on the load-bearing capacity due to the deformation of the rivet head can be excluded. The applied deformation and associated strain hardening therefore does not lead to a weakening of the rivet head, which would be shown by shearing of the rivet head protrusion under tensile load. However, the rivets with head deformation partly differ more in standard deviations, which might be caused by varying interlock values. Therefore, further studies that investigate the robustness of the joining process are recommended. The joints of the multi-range capable rivet without head deformation reach lower values for all joints. These are at a maximum of $1.81 \mathrm{kN}$. Again, the design of the ring grooves and the degree of filling are the reason for this. The investigation shows that the load-bearing cross-section of the interlock in the head area has a more significant influence on the load-bearing capacity than the load-bearing interlock between the rivet and the die-side joining part. This is also shown by the fact that all joints fail due to shearing off of the ring groove fillings. Here again, it can be seen that an increase in the number of filled ring grooves is accompanied by a linear increase in the achieved maximum force. By adding a filled ring groove, the load-bearing capacity can be almost be doubled in all cases.

The early failure of the ring groove of the joint without head forming is the reason for the low energy absorption of all joints (see Fig. 17). All values are below the other rivet geometries. The energy absorption level of the joints with rivet head deformation and the conventionally created joints are again consistently high. Deviations occur due to the low interlock in combination C. Particularly in case of the thin sheet combination A, higher energy absorption capacities of the multi-range capable rivet with head deformation can be observed. The induced stresses by the forming and the resulting pre-strengthening of the material might cause this correlation. Further studies that investigate this relationship are recommended.
Fig. 16 Comparison of the achieved maximum forces under cross tensile load for the combinations A to $\mathrm{C}$ using conventional SPR, V-SPR without head deformation and V-SPR with head deformation

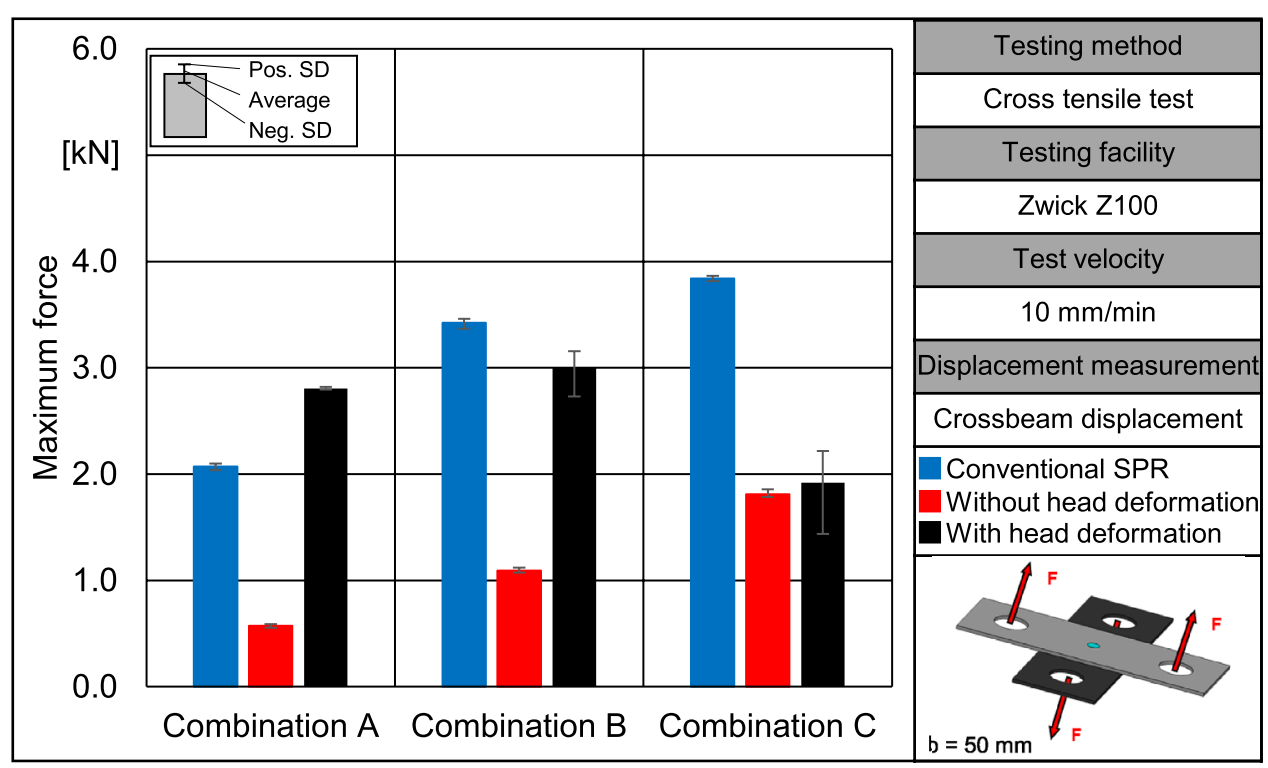


Fig. 17 Comparison of the achieved energy absorption under cross tensile load for the combinations A to $\mathrm{C}$ using conventional SPR, V-SPR without head deformation and V-SPR with head deformation

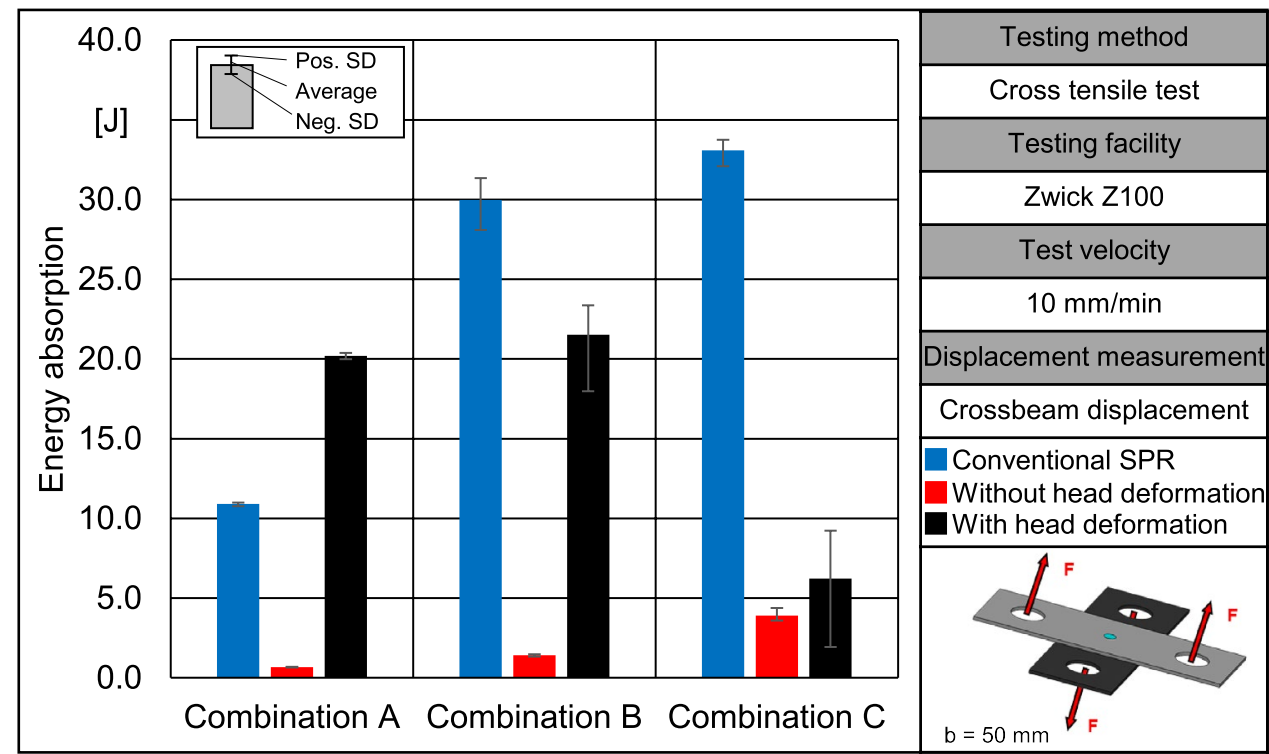

\section{Summary and outlook}

In the study presented here, a versatile semi-tubular selfpiercing riveting process was presented. In this process, the rivet is first set and subsequently the rivet head is formed by means of an extended punch-sided tool actuator technology. Afterwards, the property profile of the V-SPR process was determined using different aluminium joints. The load-bearing capacity under shear load and cross tensile load is investigated. The main conclusions derived are the following:

- In the conducted research, the process sequence of a versatile semi-tubular self-piercing riveting process is presented. The versatility is achieved by multi-range capable semi-tubular self-piercing rivets, in which the rivet head is either deformed or non-deformed. Therefore, a joining system with extended punch-sided tool actuator technology, which consists of independent and freely parameterisable punches is set up.

- The process presented enables the versatility of semitubular self-piercing riveting to be increased while at the same time achieving high joint load-bearing capacities. At the same time, a reduction of the rivet and die geometries is achieved, which increases the process efficiency.

- Both rivet geometries (with and without head deformation) offer the possibility of a large multi-range capability. Sheet thickness changes of up to $1.0 \mathrm{~mm}$ can be covered. At the same time, only one die geometry is needed to create the joints. For the same joints with conventional rivets, three rivet length and three die geometries are required.

- High load bearing capacity under shear tensile and cross tensile load is demonstrated by both rivet geometries. The forces, displacements and energy absorption achieved is significantly greater for the rivet geometry with head deformation than for the rivet geometry without head deformation.

- The load-bearing capacity of the multi-range capable rivet without head deformation is significantly influenced by the number and degree of filling of the annular ring grooves in the head area. If more ring grooves are filled, the cross-section of the loaded surface increases, which reduces occurring stresses and allows greater load-bearing capacities to be achieved. In addition, the load-bearing capacity is influenced by the stiffness of the punch-sided joining part.

- The load-bearing capacity of the riveted joints with head deformation is comparable to the behaviour of conventionally SPR joints. In part, greater forces can be reached and higher energy can be absorbed. The load-bearing capacity of the joint depends in particular on the formation of the interlock in the die-sided joining part. Due to lower penetration depths, the expansion of the rivet is reduced in case of large sheet thicknesses used, resulting in a smaller interlock formation. For this reason, a lower load-bearing capacity could be identified here. A negative influence on the load-bearing capacity due to the deformation of the rivet head could not be determined.

After the feasibility of the new V-SPR process has been proven in this paper and correspondingly high joining loadbearing capacities have been achieved, subsequent investigations will be carried out to determine influences on the joining process such as the fluctuations of the joining part properties. In addition, the joining process will be extended to multi-material structures. However, this will lead to new requirements with regard to, for example, the hardness of the rivet and the geometry of the rivet foot. Especially for the 
variant with rivet head deformation, the chances of applicability for the use of steel-aluminium joints are considered to be high, as no deformation of the joining parts is required. A modification of the rivet geometries to expand the joining spectrum is also a possibility for future investigations.

Acknowledgements Funded by the Deutsche Forschungsgemeinschaft (DFG, German Research Foundation)-TRR 285-Project-ID 418701707. The authors thank the German Research Foundation for their organisational and financial support.

Funding Open Access funding enabled and organized by Projekt DEAL. Deutsche Forschungsgemeinschaft (DFG, German Research Foundation) TRR 285-Project-ID 418701707.

\section{Declarations}

Conflict of interest Not applicable.

Open Access This article is licensed under a Creative Commons Attribution 4.0 International License, which permits use, sharing, adaptation, distribution and reproduction in any medium or format, as long as you give appropriate credit to the original author(s) and the source, provide a link to the Creative Commons licence, and indicate if changes were made. The images or other third party material in this article are included in the article's Creative Commons licence, unless indicated otherwise in a credit line to the material. If material is not included in the article's Creative Commons licence and your intended use is not permitted by statutory regulation or exceeds the permitted use, you will need to obtain permission directly from the copyright holder. To view a copy of this licence, visit http://creativecommons.org/licenses/by/4.0/.

\section{References}

1. Martinsen K, Hu SJ, Carlson BE (2015) Joining of dissimilar materials. CIRP Ann Manuf Technol 64:679-699. https://doi. org/10.1016/j.cirp.2015.05.006

2. Neugebauer R, Jäckel M, Kraus C, Kropp T (2011) Improving mechanical joining by increasing tool velocity. In: Int Automot Body Congr

3. DVS/EFB-Merkblatt $3410 \quad$ (2018) Merkblatt Stanznieten-Überblick
4. Hahn O, Klemens U (1996) Fügen durch Umformen, Nieten und Durchsetzfügen-Innovative Verbindungsverfahren für die Praxis: Dokumentation 707. Studiengesellschaft Stahlanwendung e.V.

5. Trinick RJ (2015) Method for forming a joint using a self-piercing rivet

6. Uhe B, Kuball C-M, Merklein M, Meschut G (2020) Improvement of a rivet geometry for the self-piercing riveting of high-strength steel and multi-material joints. Prod Eng 14:417-423. https://doi. org/10.1007/s11740-020-00973-w

7. Li Y, Wei Z, Li Y et al (2013) Friction Self-piercing riveting (F-SPR) of AA6061-T6 to AZ31B. In: Volume 2B: advanced manufacturing. American Society of Mechanical Engineers, pp $1-7$

8. Alves LM, Afonso RM, Martins PAF (2020) Double-sided selfpierce riveting. Int J Adv Manuf Technol 108:1541-1549. https:// doi.org/10.1007/s00170-020-05503-7

9. Mucha J (2013) The effect of material properties and joining process parameters on behavior of self-pierce riveting joints made with the solid rivet. Mater Des 52:932-946. https://doi.org/10. 1016/j.matdes.2013.06.037

10. Neugebauer R, Jesche F, Israel M (2010) Enlargement of the application range of solid punch riveting by two-piece dies. Int J Mater Form 3:999-1002. https://doi.org/10.1007/s12289-010-0938-2

11. Kappe F, Bobbert M, Meschut G (2021) New Approach for Versatile Self Piercing Riveting: Joining System and Auxiliary Part. Key Eng Mater 883:3-10. https://doi.org/10.4028/www.scientific. net/KEM.883.3

12. Novelis Global Automotive (2019) Datasheet: Novelis Advanz ${ }^{\mathrm{TM}}$ 6F-e170; aluminium sheet for exterior applications

13. DIN EN 10263-4 (2018) Steel rod, bars and wire for cold heading and cold extrusion-part 4: technical delivery conditions for steels for quenching and tempering

14. Kappe F, Bielak CR, Sartisson V et al (2021) Influence of rivet length on joint formation on self-piercing riveting process considering further process parameters. In: ESAFORM 2021. https:// doi.org/10.25518/esaform21.4277

15. DVS/EFB-Merkblatt 3480-1 (2010) Testing of properties of joints testing of properties of mechanical and hybrid (mechanical/bonded) joints-stiffness analysis of mechanical joints

Publisher's Note Springer Nature remains neutral with regard to jurisdictional claims in published maps and institutional affiliations. 